\title{
Nickel(II) complex anchored on MCM-41 for the epoxidation of styrene by oxygen
}

\author{
YANG Gang *, CHEN Xing, WANG Xiaoli, XING Weihong, XU Nanping \\ State Key Laboratory of Materials-Oriented Chemical Engineering, Nanjing University of Technology, Nanjing 210009, Jiangsu, China
}

A R T I C L E I N F O

Article history:

Received 23 January 2013

Accepted 12 March 2013

Published 20 July 2013

Keywords:

Nickel Schiff base complex

MCM-41 molecular sieve

Styrene epoxidation

Molecular oxygen

\begin{abstract}
A B S T R A C T
A heterogeneous catalyst, MCM-41-Ni, was synthesized by anchoring a nickel(II) Schiff base complex onto amino-modified MCM-41. The catalyst was characterized by small angle X-ray diffraction, nitrogen adsorption, infrared spectroscopy, thermal gravimetric analysis, inductively coupled plasma and $\mathrm{C}, \mathrm{H}, \mathrm{N}$ elemental analysis, and transmission electron microscopy. MCM-41-Ni showed excellent catalytic activity for the epoxidation of styrene with $\mathrm{O}_{2}$ as oxidant with high styrene conversion (95.2\%) and epoxide selectivity (66.7\%). The influence of reaction temperature, catalyst amount, solvent, and reaction time was studied. MCM-41-Ni showed good recyclability and can be reused four times.
\end{abstract}

(C) 2013, Dalian Institute of Chemical Physics, Chinese Academy of Sciences. Published by Elsevier B.V. All rights reserved.

\section{Introduction}

Styrene oxide is a key industrial intermediate in the production of fine chemicals and pharmaceuticals [1,2]. At present, styrene oxide is synthesized using an organic peracid as oxidant or by a chlorohydrin process. Because both processes use hazardous chemicals and produce a lot of waste, exploring environmentally benign aerobic catalytic processes based on environmentally friendly reusable heterogeneous catalysts has been a subject of great interest. Transition metal complexes are good epoxidation catalysts [3-6]. However, these homogeneous catalysts suffer from several disadvantages, such as difficult separation and loss of precious metal complexes in the reactions $[7,8]$. These problems can be solved by anchoring the homogeneous catalysts onto chemically modified support materials [7].

Mesoporous silica materials have attracted attention due to their large tunable pore dimensions, high surface areas, and diversity in surface functionalization $[9,10]$. Many transition metal complexes supported on chemically modified silica have been studied for the catalysis of the epoxidation of styrene. Jana et al. [11] reported the preparation of a copper(II) complex anchored on MCM-41 and its use in the epoxidation of styrene using tert-BuOOH as oxidant that gave a high conversion (97.0\%) and epoxide selectivity (89.0\%). Wang et al. [12] immobilized an alanine-salicylaldehyde Schiff base chromium(III) complex on mesoporous silica gel and reported that the immobilized complex exhibited high catalytic performance in the epoxidation of styrene using $\mathrm{H}_{2} \mathrm{O}_{2}$ as oxidant with good conversion (80.2\%) and epoxide selectivity (77.0\%).

Among the various oxidants, molecular oxygen is the most desirable oxidant for the epoxidation of alkenes because it is a green oxidant and its byproduct is water [13-15]. Yang et al. [16] reported the tethering of $\mathrm{Cu}(\mathrm{II}), \mathrm{Co}(\mathrm{II})$, and $\mathrm{Fe}(\mathrm{III})$ tetrahydrosalen and salen complexes onto amino-functionalized SBA-15. The resulting catalysts were applied in the epoxidation of styrene using $\mathrm{O}_{2}$ as oxidant, but a sacrificial co-reductant, isobutyraldehyde, was necessary. The $\mathrm{Co}(\mathrm{II})-\left[\mathrm{H}_{4}\right]$ Salen-SBA catalyst achieved $77.5 \%$ conversion and $63.7 \%$ epoxide selectivity. Li et al. [17] reported a novel oxovanadium(IV) catalyst,

\footnotetext{
* Corresponding author. Tel: +86-25-83172291; Fax: +86-25-83172292; E-mail: yanggang@njut.edu.cn This work was supported by the National Natural Science Foundation of China (20576052). 


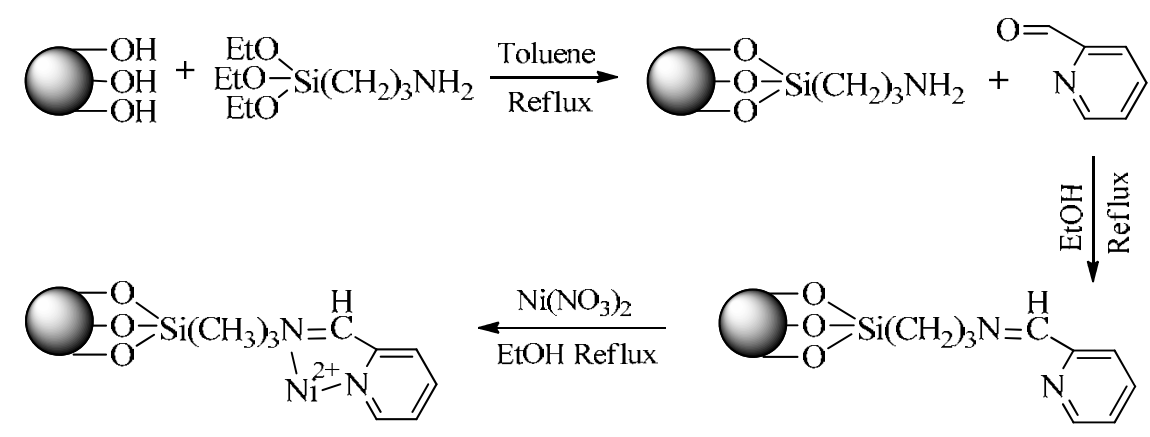

Scheme 1. Synthesis of MCM-41-Ni.

which showed high conversion (91.2\%) and epoxide selectivity $(50.2 \%)$ with air as oxidant, but a sacrificial co-reductant, isobutyraldehyde, was also necessary. Gao et al. [18] reported the preparation of Co(III)-modified SBA-15 and that the catalyst showed high conversion and selectivity in the epoxidation of cyclohexene with a sacrificial co-reductant. The catalytic epoxidation of alkenes by $\mathrm{O}_{2}$ without a co-reductant is attractive and challenging.

Nickel-based catalysts are used in many reactions [19-25]. Chatterjee et al. [26] reported the catalytic activities of Schiff base complexes of nickel(II) in the epoxidation of olefins with $\mathrm{NaOCl}$ and $\mathrm{KHSO}_{5}$ as oxidants. Bhunia et al. [27] prepared a heterogeneous nickel(II) Schiff base catalyst, which showed excellent catalytic activity for the epoxidation of olefins using tert-BuOOH as oxidant. However, there are few reports on supported nickel-based catalysts for the epoxidation of styrene using $\mathrm{O}_{2}$ as oxidant without a co-reductant. Here we report the preparation (depicted in Scheme 1), characterization, and catalytic performance of a heterogeneous nickel(II) Schiff base-functionalized MCM-41 catalyst. The catalyst showed excellent catalytic activity in the epoxidation of styrene using $\mathrm{O}_{2}$ as oxidant without a sacrificial reductant.

\section{Experimental}

\subsection{Synthesis of aminopropyl functionalized MCM-41 mesoporous material MCM-41- $\mathrm{NH}_{2}$}

The pure siliceous MCM-41 was activated at $150{ }^{\circ} \mathrm{C}$ for $3 \mathrm{~h}$. Pure siliceous MCM-41 (3 g) was suspended in dry toluene $(100 \mathrm{ml})$, and 3-aminopropytrimethoxysilane (99\%, $3 \mathrm{~g}$ ) was added to it. The suspension was stirred and refluxed under nitrogen atmosphere for $24 \mathrm{~h}$. The product MCM-41- $\mathrm{NH}_{2}$ was filtered, washed with toluene, then washed with dichloromethane, and dried at $100{ }^{\circ} \mathrm{C}$ for $5 \mathrm{~h}$.

\subsection{Synthesis of Schiff base functionalized MCM-41 mesoporous material MCM-41-L}

White solid MCM-41- $\mathrm{NH}_{2}$ (2 g) was added to absolute ethanol $(99.7 \%, 60 \mathrm{ml})$ in a $100 \mathrm{ml}$ round bottomed flask followed by 2-pyridinecarboxaldehyde (98\%, $0.8018 \mathrm{~g})$. The mixture was stirred and refluxed under nitrogen atmosphere for $24 \mathrm{~h}$. The resulting yellow solid MCM-41-L was filtered, washed with ethanol, then washed with dichloromethane, and dried at 100 ${ }^{\circ} \mathrm{C}$ for $5 \mathrm{~h}$.

\subsection{Synthesis of MCM-41-Ni}

MCM-41-Ni was prepared by mixing a solution of $\mathrm{Ni}\left(\mathrm{NO}_{3}\right)_{2} \cdot 6 \mathrm{H}_{2} \mathrm{O}(0.8294 \mathrm{~g})$ in ethanol $(50 \mathrm{ml})$, and the MCM-41-L (1.1 g) was added with stirring to keep it in suspension at $60{ }^{\circ} \mathrm{C}$ for $24 \mathrm{~h}$. The beige colored solid was filtered, washed with ethanol using a Soxhlet apparatus, and dried at 70 ${ }^{\circ} \mathrm{C}$ in a vacuum oven for $6 \mathrm{~h}$.

For comparison, four catalysts, namely, MCM-41-Co, MCM-41-Fe, MCM-41-Cu, and MCM-41-Ni(Cl), were prepared by the same procedure. For these, $\mathrm{Ni}\left(\mathrm{NO}_{3}\right)_{2} \cdot 6 \mathrm{H}_{2} \mathrm{O}$ was replaced by $\mathrm{Co}\left(\mathrm{CH}_{3} \mathrm{COO}\right)_{2} \cdot 4 \mathrm{H}_{2} \mathrm{O}(0.7104 \mathrm{~g}), \mathrm{Fe}\left(\mathrm{NO}_{3}\right)_{3} \cdot 9 \mathrm{H}_{2} \mathrm{O}(1.1523 \mathrm{~g})$, $\mathrm{Cu}\left(\mathrm{NO}_{3}\right)_{2} \cdot 3 \mathrm{H}_{2} \mathrm{O}(0.6891 \mathrm{~g})$, and $\mathrm{NiCl}_{2} \cdot 6 \mathrm{H}_{2} \mathrm{O}(0.6779 \mathrm{~g})$, respectively.

\subsection{Characterization of the catalysts}

Powder X-ray diffraction (XRD) of the samples was measured on a Rigaku D/Max-RA instrument with Ni filtered $\mathrm{Cu} K_{\alpha}$ radiation $(\lambda=0.154178 \mathrm{~nm})$ at $40 \mathrm{kV}$ and $40 \mathrm{~mA}$ in the range of $1.5^{\circ}-8^{\circ}$ in steps of $1^{\circ} / \mathrm{min}$. $\mathrm{N}_{2}$ adsorption isotherms were recorded at $-196{ }^{\circ} \mathrm{C}$ on a Micromeritics ASAP-2010 instrument. The samples were outgassed under vacuum at $90{ }^{\circ} \mathrm{C}$ for $6 \mathrm{~h}$ before measurement. The specific surface area was calculated by the BET method, and the pore size distribution was measured from the desorption branch by the BJH method. Elemental analysis $(\mathrm{C}, \mathrm{H}, \mathrm{N})$ was performed using a Vario EL cube elemental analyzer. The metal content was measured by inductively coupled plasma-atomic emission spectroscopy (ICP-AES) on a PE 7000DV spectrometer. Fourier transform infrared (FT-IR) spectroscopy was carried out on a Nicolet 360 spectrophotometer with anhydrous $\mathrm{KBr}$ as standard. Thermal gravimetric (TG) analysis was performed with a Netzsch STA 449 F3 instrument. High resolution transmission electron microscopy (HRTEM) was carried out on a JEOL JEM-2100F operating at $200 \mathrm{kV}$.

\subsection{Catalytic reactions}

The epoxidation of styrene with $\mathrm{O}_{2}$ was carried out in a 50 $\mathrm{ml}$ three-necked round bottom flask equipped with a conden- 


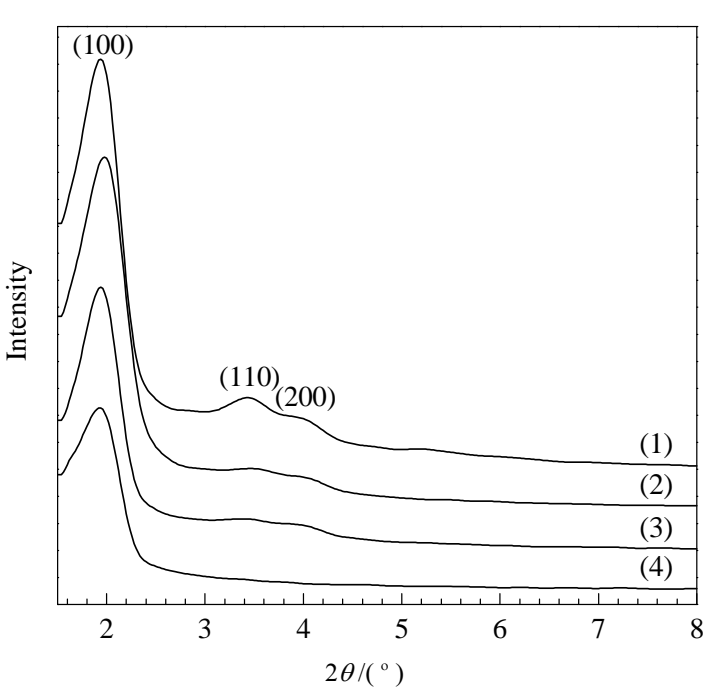

Fig. 1. XRD patterns of MCM-41 (1), MCM-41- $\mathrm{NH}_{2}$ (2), MCM-41-L (3), and MCM-41-Ni (4).

ser. In a typical run, $3 \mathrm{mmol}$ of styrene and appropriate amounts of solvent and catalyst were added to the flask. The mixture was stirred vigorously by a magnetic stirrer and heated to the reaction temperature. The reaction was started by bubbling $\mathrm{O}_{2}$ at a flow rate controlled by a flowmeter at atmospheric pressure. After the reaction, the liquid product was separated by centrifugation and quantified with a gas chromatograph equipped with an FID detector (SP6800A, SE-30 capillary column $50 \mathrm{~m} \times 0.25 \mathrm{~mm} \times 0.25 \mu \mathrm{m}$ ) with bromobenzene as an internal standard.

After the reaction, the catalyst was separated from the reaction mixture by centrifugation and washed repeatedly with ethanol and 1,4-dioxane, and then it was reused for the next run under the same reaction conditions.

\section{Results and discussion}

\subsection{Characterization of catalysts}

The small angle XRD patterns of MCM-41, MCM-41- $\mathrm{NH}_{2}$, MCM-41-L, and MCM-41-Ni are shown in Fig. 1. The MCM-41 sample showed three diffraction peaks indexed as the (100), (110), and (200) diffraction peaks of the hexagonal lattice of mesoporous MCM-41 [28]. Although the samples were modified by an organic group and metal ions, a strong (100) peak at $2 \theta \approx 1.96^{\circ}$ together with two weak (110) and (200) peaks was

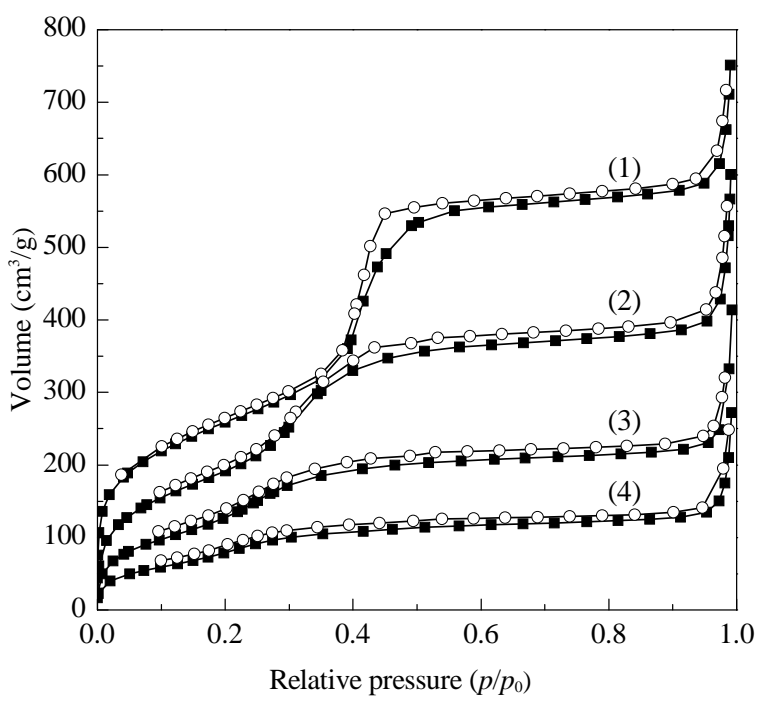

Fig. 3. $\mathrm{N}_{2}$ adsorption-desorption isotherms of MCM-41 (1), MCM-41$\mathrm{NH}_{2}$ (2), MCM-41-L (3), and MCM-41-Ni (4).

observed, indicating the ordered hexagonal structure of the samples. However, the peak intensity became weaker gradually with further modified samples, demonstrating the introduction of organic groups into the mesopores of MCM-41. After the immobilization of the nickel(II) Schiff base complex, the intensity of the peaks for the (110) and (200) reflections were further decreased. This decrease in the intensity of the peaks may indicate the lowering of local order, e.g. variation in wall thickness, or may be the result of less scattering contrast between the channel wall of the silicate framework and the nickel(II) complex present in the pores [11]. The position of the (100) reflection remained the same, demonstrating that the basic hexagonal pore arrangement was kept [29,30].

The HRTEM micrographs of MCM-41, MCM-41-NH2, MCM-41-L, and MCM-41-Ni are shown in Fig. 2. The regular arrangement of the pores can be clearly observed for all these materials. The pore diameter of MCM-41, MCM-41-NH2, MCM-41-L, and MCM-41-Ni are 3.2, 2.4, 2.1, and $1.8 \mathrm{~nm}$, respectively. The pore diameter gradually decreased with increased modification steps. After the immobilization of the nickel(II) Schiff base complex onto MCM-41, the hexagonal pores remained intact, but the regular arrangement of the pores was lower.

The $\mathrm{N}_{2}$ adsorption isotherms of MCM-41, MCM-41- $\mathrm{NH}_{2}$, MCM-41-L, and MCM-41-Ni are depicted in Fig. 3. All the samples exhibited type IV isotherms typical of a mesoporous solid
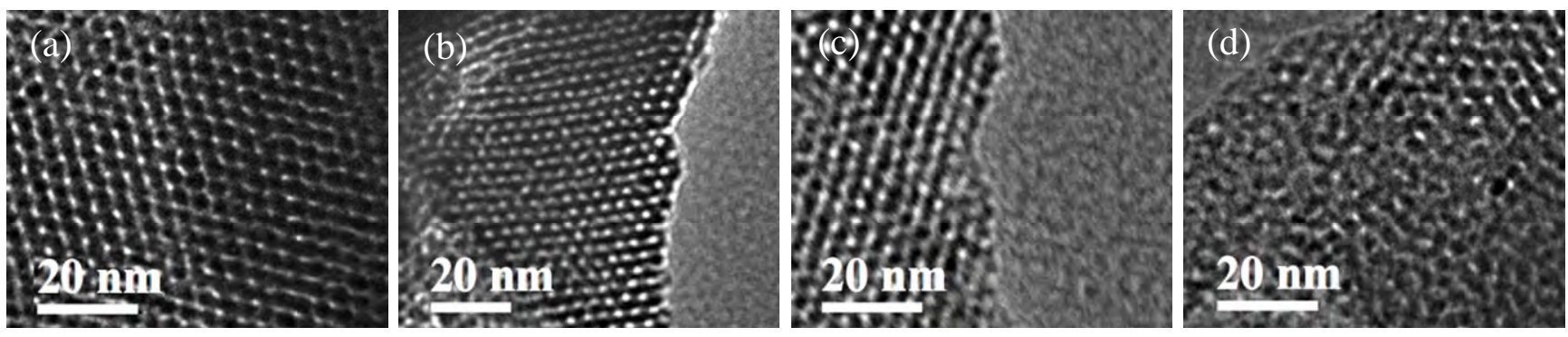

Fig. 2. HRTEM images of MCM-41 (a), MCM-41-NH 2 (b), MCM-41-L (c), and MCM-41-Ni (d). 
Table 1

Composition and textural parameters of the samples.

\begin{tabular}{lcccc}
\hline Sample & $\begin{array}{c}A_{\mathrm{BET}} \\
\left(\mathrm{m}^{2} / \mathrm{g}\right)\end{array}$ & $\begin{array}{c}V_{\mathrm{p}} \\
\left(\mathrm{cm}^{3} / \mathrm{g}\right)\end{array}$ & $\begin{array}{c}\text { Pore diameter } \\
(\mathrm{nm})\end{array}$ & $\begin{array}{c}\mathrm{C}, \mathrm{H}, \mathrm{N} \text { content } \\
(\mathrm{wt} \%)\end{array}$ \\
\hline MCM-41 & 917 & 1.15 & 3.28 & $0,0,0$ \\
MCM-41-NH & 706 & 0.89 & 2.53 & $8.43,2.48,2.62$ \\
MCM-41-L & 444 & 0.56 & 2.26 & $18.42,2.38,4.31$ \\
MCM-41-Ni & 280 & 0.38 & 2.02 & $14.58,2.92,5.13$ \\
\hline
\end{tabular}

and had sharp capillary condensation steps at relative pressures of $0.2 \leq p / p_{0} \leq 0.5$. The pore size distributions of these samples were very narrow with average pore size at 2.02 and $3.28 \mathrm{~nm}$. The pure MCM-41 sample had the largest BET surface area of $917 \mathrm{~m}^{2} / \mathrm{g}$ and pore volume $\left(V_{\mathrm{p}}\right)$ of $1.15 \mathrm{~cm}^{3} / \mathrm{g}$ (Table 1 ). The shift to low relative pressure $\left(p / p_{0}\right)$ was assigned to the introduction of bulky organic groups and metal ions, which is consistent with the XRD results. As listed in Table 1, the BET surface area, pore volume, and pore diameter gradually decreased with more modification steps in comparison to the MCM-41, which was probably due to the existence of many Schiff base ligands and nickel(II) Schiff base complexes on the surface of the pores. With the increasing of the modification steps, the adsorption and desorption isotherms gradually did not close at low $p / p_{0}$. This was probably due to the existence of many Schiff base ligands and nickel(II) Schiff base complexes on the materials [31].

The FT-IR spectra of MCM-41, MCM-41-NH2, MCM-41-L, and MCM-41-Ni are shown in Fig. 4. MCM-41 showed a band at $3442 \mathrm{~cm}^{-1}$, which can be attributed to the silanol OH groups. The bands at 1078 and $808 \mathrm{~cm}^{-1}$ corresponded to the asymmetric and symmetric $\mathrm{Si}-\mathrm{O}-\mathrm{Si}$ vibrations. The weak $\mathrm{C}-\mathrm{H}$ stretches observed at 2980 and $2942 \mathrm{~cm}^{-1}$ and the bands in the $1550-1250 \mathrm{~cm}^{-1}$ region can be assigned to the bending vibration band of $\mathrm{C}-\mathrm{H}$. These confirmed the attachment of the aminopropyl group on the surface of MCM-41. The FT-IR spectrum of MCM-41-L showed a sharp peak at $1652 \mathrm{~cm}^{-1}$ due to a $\mathrm{C}=\mathrm{N}$

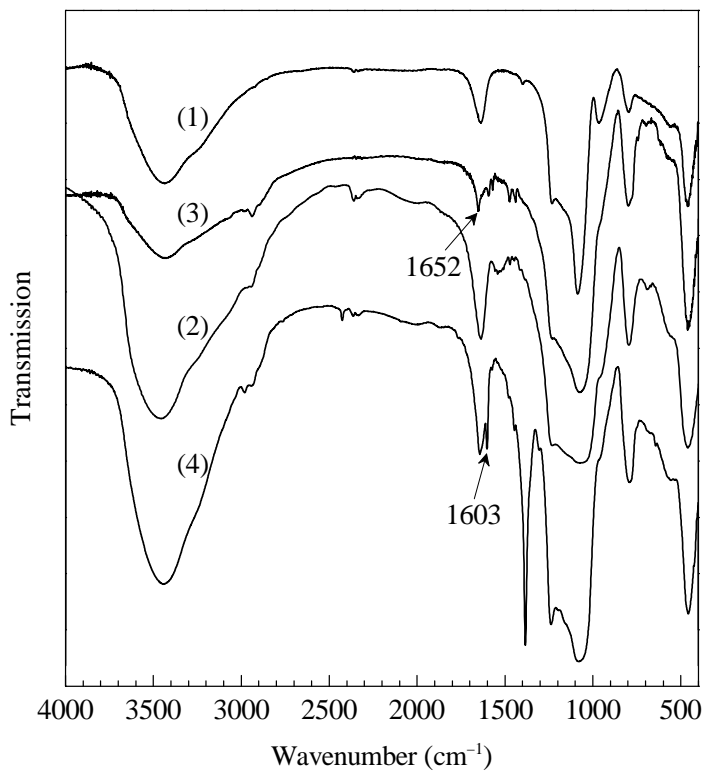

Fig. 4. FT-IR spectra of MCM-41 (1), MCM-41- $\mathrm{NH}_{2}$ (2), MCM-41-L (3), and MCM-41-Ni (4).

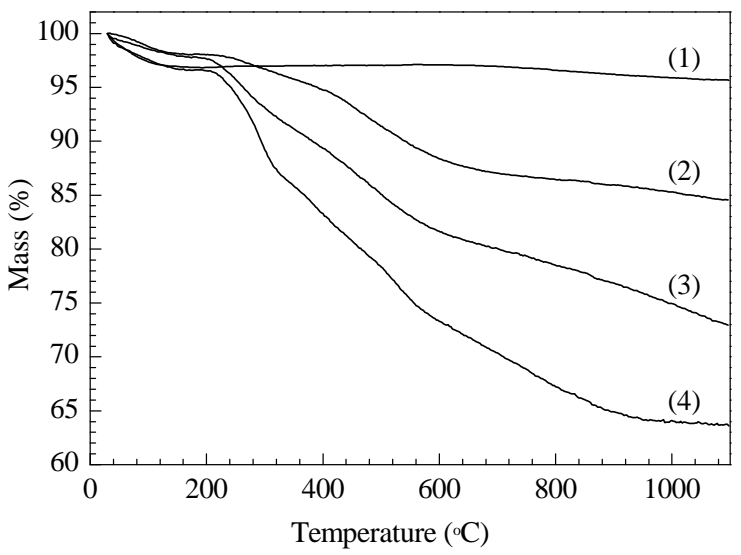

Fig. 5. TG curves of MCM-41 (1), MCM-41-NH $\mathrm{NH}_{2}$ (2), MCM-41-L (3), and MCM-41-Ni (4).

stretching vibration, which confirmed a 2-pyridinecarboxaldehyde functionalized group from a chemical reaction with MCM-41- $\mathrm{NH}_{2}$. After the complexation of nickel with MCM-41-L, the $\mathrm{C}=\mathrm{N}$ stretching vibration frequency was shifted to a lower frequency, indicating the formation of a metal-ligand bond [32]. The strong absorption at $1388 \mathrm{~cm}^{-1}$ was due to the NO-stretching modes, $v\left(\mathrm{NO}^{3-}\right)$, indicating that nickel ions were introduced into the hybrid materials via their coordination to MCM-41-L

The elemental analysis data are shown in Table 1 . These showed an increase in the mass percentages of $\mathrm{C}, \mathrm{H}$, and $\mathrm{N}$ with the increase in modification steps before forming MCM-41-Ni. This confirmed the immobilization of the Schiff base ligand on MCM-41 support. The nickel content of the catalyst was 5.24 wt $\%$. For MCM-41-Ni, the elemental analysis showed the $\mathrm{N} / \mathrm{Ni}$ molar ratio $\approx 4.10$, which indicated that the nickel ions have a $\mathrm{N}_{2}$ ligand environment as shown in Scheme 1.

The TG curves of MCM-41, MCM-41- $\mathrm{NH}_{2}$, MCM-41-L, and MCM-41-Ni are shown in Fig. 5. All the samples showed a mass loss below $220^{\circ} \mathrm{C}$ due to the removal of physically adsorbed water and solvent inside the pores. MCM-41-NH2, MCM-41-L, and MCM-41-Ni showed a large mass loss in the temperature range of $220-900{ }^{\circ} \mathrm{C}$ due to the decomposition of the organic groups and complexes. With the increase in modification steps, the mass loss increased. All the materials were stable below $220^{\circ} \mathrm{C}$.

\subsection{Epoxidation of styrene with $\mathrm{O}_{2}$ catalyzed by the catalysts}

Because the triplet ground state of $\mathrm{O}_{2}$ does not favor reactions with singlet state organic compounds [33], the epoxidation of styrene with $\mathrm{O}_{2}$ is a challenging subject. In this study, five metal complex catalysts were prepared to find out which metal species was the most active for the reaction. Table 2 shows the performance of the different transition metal catalysts based on MCM- 41 for the epoxidation of styrene with $\mathrm{O}_{2}$ using 1,4-dioxane as solvent. MCM-41-Ni was the best catalyst for the epoxidation of styrene with the highest styrene conversion (95.2\%) and styrene oxide selectivity (66.7\%). When the starting precursor was changed from nickel nitrate to nickel 
Table 2

Epoxidation of styrene with $\mathrm{O}_{2}$ catalyzed by different metal complex catalysts.

\begin{tabular}{|c|c|c|c|c|c|c|}
\hline Catalyst & $\begin{array}{c}\text { Metal content } \\
(\mathrm{wt} \%)\end{array}$ & $\begin{array}{c}\text { Surface area } \\
\left(\mathrm{m}^{2} / \mathrm{g}\right)\end{array}$ & $\begin{array}{l}\text { Pore volume } \\
\left(\mathrm{cm}^{3} / \mathrm{g}\right)\end{array}$ & $\begin{array}{c}\text { Pore diameter } \\
(\mathrm{nm})\end{array}$ & $\begin{array}{c}\text { Styrene conversion } \\
(\%) \\
\end{array}$ & $\begin{array}{c}\text { Epoxide selectivity } \\
(\%)\end{array}$ \\
\hline Blank & 0 & 0 & 0 & 0 & 61.7 & 29.5 \\
\hline MCM-41 & 0 & 917 & 1.15 & 3.28 & 97.7 & 0 \\
\hline MCM-41-Ni & 5.24 & 280 & 0.38 & 2.02 & 95.2 & 66.7 \\
\hline MCM-41-Ni a & 5.24 & 280 & 0.38 & 2.02 & 0 & 0 \\
\hline MCM-41-Ni(Cl) & 5.13 & 265 & 0.40 & 2.02 & 92.5 & 35.3 \\
\hline MCM-41-Cu & 6.17 & 142 & 0.24 & 2.02 & trace & trace \\
\hline MCM-41-Fe & 7.43 & 263 & 0.44 & 2.26 & 91.7 & 49.3 \\
\hline MCM-41-Сo & 5.50 & 182 & 0.33 & 2.02 & 99.9 & 59.1 \\
\hline
\end{tabular}

Reaction conditions: styrene $3 \mathrm{mmol}, 1,4$-dioxane $10 \mathrm{ml}$, catalyst $50 \mathrm{mg}, 100{ }^{\circ} \mathrm{C}, \mathrm{O}_{2} 6 \mathrm{ml} / \mathrm{min}, 6 \mathrm{~h}$.

a Hydroquinone ( $0.3 \mathrm{mmol})$ was added to the reaction.

chloride, the resulting sample was notably inferior, namely, it gave $92.5 \%$ styrene conversion and $35.3 \%$ epoxide selectivity. This result was similar to the observation of Zhan et al. [34]. Further elucidation of this phenomenon is needed in future studies. In order to study the reaction mechanism, we added a small quantity of free radical scavenger, hydroquinone $[0.3$ $\mathrm{mmol}$ ), to the MCM-41-Ni reaction system. The conversion of styrene to styrene oxide was found to be almost zero. Therefore, the reaction mechanism follows a free radical mechanism [35].

\subsection{Reaction conditions for the epoxidation of styrene catalyzed by MCM-41-Ni}

Table 3 presents the effect of various solvents on the epoxidation of styrene with $\mathrm{O}_{2}$ over MCM-41-Ni at $100{ }^{\circ} \mathrm{C}$. The solvent played a vital role in the epoxidation. No epoxidation occurred when pyridine or toluene was used as the solvent. Although a high styrene conversion was obtained in dimethyl sulfoxide, the epoxide selectivity was low. When $\mathrm{N}, \mathrm{N}$-dimethylformamide was used as the solvent, both styrene conversion and epoxide selectivity were low. 1,4-Dioxane was a good solvent giving a high styrene conversion (95.2\%) and epoxide selectivity (66.7\%). Shi et al. [36] used 1,4-dioxane as solvent in the epoxidation of styrene with $\mathrm{O}_{2}$ and obtained styrene conversion and selectivity for styrene oxide of $85 \%$ and $69 \%$, re-
Table 3

Effect of various solvents on the epoxidation of styrene over MCM-41-Ni.

\begin{tabular}{lcccc}
\hline \multirow{2}{*}{ Solvent } & Styrene con- & \multicolumn{3}{c}{ Product selectivity (\%) } \\
\cline { 3 - 5 } & version (\%) & Epoxide & Benzaldehyde & Others \\
\hline$N, N$-dimethylformamide & 23.9 & 24.5 & 22.1 & 53.4 \\
Dimethyl sulfoxide & 92.8 & 21.5 & 41.5 & 37.0 \\
Cyclohexanone & 54.7 & 34.2 & 47.9 & 17.9 \\
Pyridine & 0 & 0 & 0 & 0 \\
1,4-dioxane & 95.2 & 66.7 & 14.4 & 18.9 \\
Toluene & 0 & 0 & 0 & 0 \\
\hline
\end{tabular}

Reaction conditions: styrene $3 \mathrm{mmol}, 1,4$-dioxane $10 \mathrm{ml}$, catalyst $50 \mathrm{mg}$, $100^{\circ} \mathrm{C}, \mathrm{O}_{2} 6 \mathrm{ml} / \mathrm{min}, 6 \mathrm{~h}$.

spectively. Based on the solvent studies, it can be concluded that 1,4-dioxane is the most suitable solvent for this oxidation system.

The influence of reaction temperature on the epoxidation of styrene over MCM-41-Ni is depicted in Fig. 6(a). The conversion of styrene gradually increased with increasing reaction temperature at first. For example, the styrene conversion was $14.2 \%$ at $50{ }^{\circ} \mathrm{C}$, which quickly rose to $45.2 \%$ at $70{ }^{\circ} \mathrm{C}$, and to $95.2 \%$ at $100{ }^{\circ} \mathrm{C}$. However, the conversion of styrene dropped to $85.7 \%$ with a further increase in the reaction temperature to $110{ }^{\circ} \mathrm{C}$. The selectivity for epoxide followed the variation of styrene conversion with temperature, and it first increased from $27.9 \%$ at $50{ }^{\circ} \mathrm{C}$ to the maximum $(66.7 \%)$ at $100{ }^{\circ} \mathrm{C}$ and

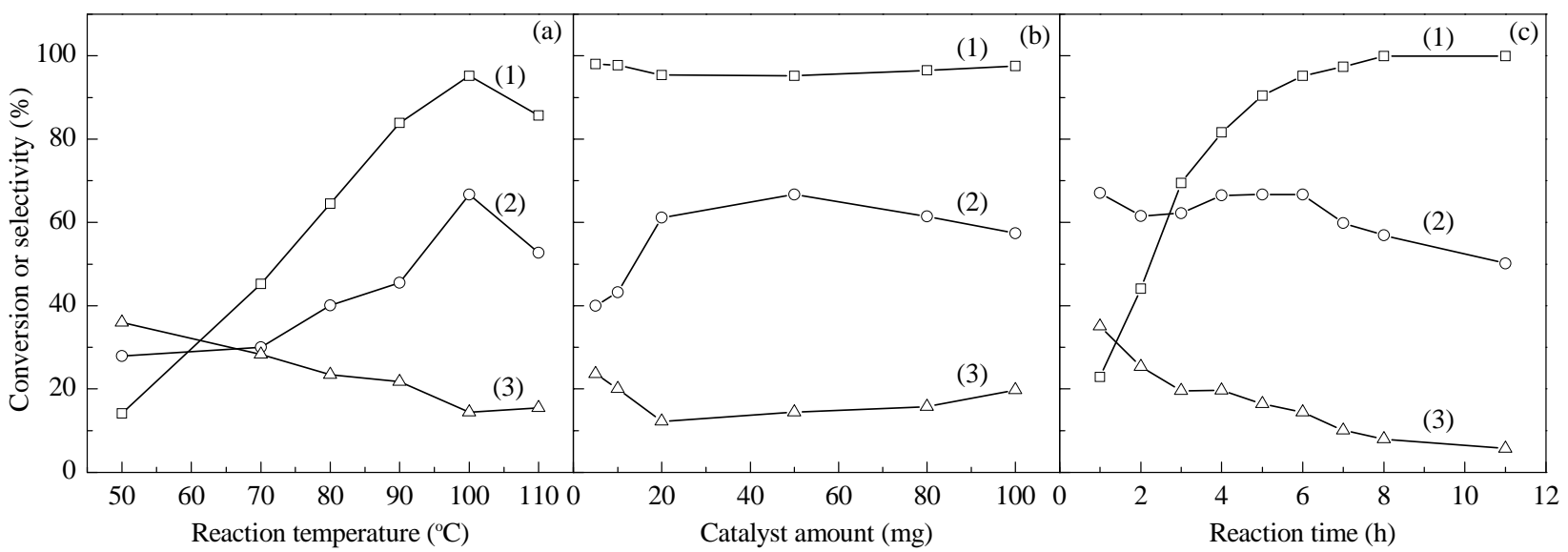

Fig. 6. Effect of reaction conditions on the epoxidation of styrene catalyzed by MCM-41-Ni. (a) Reaction temperature; (b) Catalyst amount; (c) Reaction time. (1) Styrene conversion; (2) Epoxide selectivity; (3) Benzaldehyde selectivity. Reaction conditions: styrene 3 mmol, 1,4-dioxane 10 ml, catalyst $50 \mathrm{mg}$ (except for (b)), $100^{\circ} \mathrm{C}$ (except for (a)), $\mathrm{O}_{2} 6 \mathrm{ml} / \mathrm{min}, 6 \mathrm{~h}$ (except for (c)). 
then quickly fell to $52.7 \%$ at $110{ }^{\circ} \mathrm{C}$. When the reaction temperature was too low, it was difficult to initiate the reaction. When the reaction temperature was too high, the polymerization of styrene occurred and byproducts increased. A proper reaction temperature is needed for the formation of epoxide.

The effect of the MCM-41-Ni amount on the epoxidation of styrene is illustrated in Fig. 6(b). When the amount of MCM-41-Ni was increased from 5 to $100 \mathrm{mg}$, the conversion of styrene was more or less constant at $96.7 \%$. With increasing amount of catalyst, the active centers of the catalyst increased. When the amount of catalyst reached $50 \mathrm{mg}$, the epoxide selectivity reached the maximum value $(66.7 \%)$. Then it began to show a small decrease from $66.7 \%$ to $57.4 \%$. This was due to more byproducts due to a further increase of the active centers of the catalyst.

The influence of reaction time on the epoxidation of styrene with $\mathrm{O}_{2}$ over MCM-41-Ni at $100{ }^{\circ} \mathrm{C}$ was also investigated. The results are shown in Fig. 6(c). At the beginning of the reaction, the conversion of styrene was zero, and it gradually increased to $22.9 \%$ in $1 \mathrm{~h}$, to $44.1 \%$ in $2 \mathrm{~h}$, and to $99.9 \%$ in $11 \mathrm{~h}$, showing the induction period characteristic of a radical reaction. However, the epoxide selectivity was approximately maintained at the value of $65.0 \%$ for $6 \mathrm{~h}$, and then it began to decrease as the reaction time increased. Prolonged reaction time led to the over oxidation of styrene to acid and polymerization of styrene, which resulted in the decrease of epoxide selectivity [37].

\section{4. $\quad$ Recycling studies}

Catalyst recycling experiments were performed with the repeated use of MCM-41-Ni at $100{ }^{\circ} \mathrm{C}$ for $6 \mathrm{~h}$. It can be seen from Fig. 7 that with the reuse of MCM-41-Ni five times, the styrene conversion was maintained almost unchanged, while the selectivity for epoxide only showed a small decrease from $66.7 \%$ to $61.6 \%$ in the first four reuse and then it quickly decreased to $45.7 \%$ in the fifth reuse. After each use, the amount of nickel in the reaction mixture (after removal of catalyst) was detected by ICP-AES. Negligible leaching of nickel in the solution was detected. The analysis indicated the stability and the recyclability of MCM-41-Ni in the epoxidation of styrene with $\mathrm{O}_{2}$.

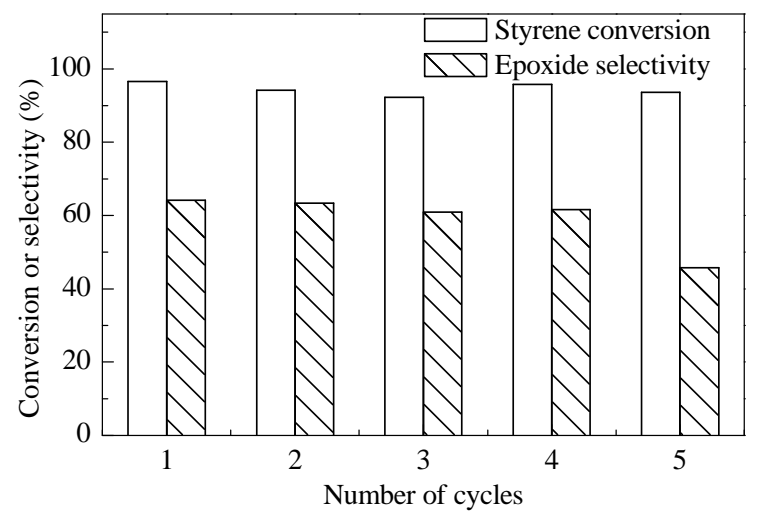

Fig. 7. Reusability of MCM-41-Ni for the epoxidation of styrene with $\mathrm{O}_{2}$. Reaction conditions: styrene $3 \mathrm{mmol}, 1,4$-dioxane $10 \mathrm{ml}$, catalyst $50 \mathrm{mg}$, $100{ }^{\circ} \mathrm{C}, \mathrm{O}_{2} 6 \mathrm{ml} / \mathrm{min}, 6 \mathrm{~h}$.

\section{Conclusions}

We successfully anchored a nickel(II) Schiff base complex onto mesoporous MCM-41. MCM-41-Ni catalyzed the epoxidation of styrene with molecular oxygen without a sacrificial reductant with excellent catalytic performance. The excellent catalytic performance was obtained with the appropriate reaction temperature and solvent. 1,4-dioxane is a suitable solvent for the catalyst. The catalyst showed excellent stability and recyclability.

\section{References}

[1] Grigoropoulou G, Clark J H, Elings J A. Green Chem, 2003, 5: 1

[2] Selvaraj M, Lee T G. J Phys Chem B, 2006, 110: 21793

[3] Canali L, Sherrington D C. Chem Soc Rev, 1999, 28: 85

[4] Tsuji Y, Ohta T, Ido T, Minbu H, Watanabe Y. J Organomet Chem, 1984, 270: 333

[5] Wang R M, Hao Ch J, He Y F, Wang Y P, Xia Ch G. Polym Adv Technol, 2002, 13: 6

[6] Zhao J Q, Han J P, Zhang Y Ch.J Mol Catal A, 2005, 231: 129

[7] Shamim T, Gupta M, Paul S. J Mol Catal A, 2009, 302: 15

[8] Bahramian B, Mirkhani V, Moghadam M, Tangestaninejad S. Catal Commun, 2006, 7: 289

[9] Liu R, Zhang Y, Zhao X, Agarwal A, Mueller L J, Feng P Y. J Am Chem Soc, 2010, 132: 1500

[10] Liu R, Zhang Y, Feng P Y.J Am Chem Soc, 2009, 131: 15128

[11] Jana S, Dutta B, Bera R, Koner S. Langmuir, 2007, 23: 2492

[12] Wang X L, Wu G D, Wei W, Sun Y H. Catal Lett, 2010, 136: 96

[13] Tang Q H, Wang Y, Liang J, Wang P, Zhang Q H, Wan H L. Chem Commun, 2004: 440

[14] Shirin Z, Hammes B S, Young V G Jr, Borovik A S. J Am Chem Soc, 2000, 122: 1836

[15] Cicco S R, Latronico M, Mastrorilli P, Suranna G P, Nobile C F. J Mol Catal A, 2001, 165: 135

[16] Yang Y, Zhang Y, Hao Sh J, Kan Q B. Chem Eng J, 2011, 171: 1356

[17] Li Zh F, Liu L L, Hu J, Liu H, Wu Sh J, Huo Q Sh, Guan J Q, Kan Q B. Appl Organomet Chem, 2012, 26: 252

[18] Gao P F, Zhang T M, Zhou Y, Zhao Y X. Chin J Catal (高鹏飞, 张铁明, 周媛, 赵永祥. 催化学报), 2011, 32: 166

[19] Nam W, Kim H J, Kim S H, Ho R Y N, Valentine J S. Inorg Chem, 1996, 35: 1045

[20] Zaera F. Catal Today, 2003, 81: 149

[21] Koola J D, Kochi J K. Inorg Chem, 1987, 26: 908

[22] Kinneary J F, Wagler T R, Burrows C J. Tetrahedron Lett, 1988, 29: 877

[23] Nam W, Valentine J S. J Am Chem Soc, 1993, 115: 1772

[24] Dangel B, Clarke M, Haley J, Sames D, Polt R. J Am Chem Soc, 1997, 119: 10865

[25] Rispens M T, Gelling O J, de Vries A M, Meetsma A, van Bolhuis F, Feringa B L. Tetrahedron, 1996, 52: 3521

[26] Chatterjee D, Mitra A. J Mol Catal A, 1999, 144: 363

[27] Bhunia S, Koner S. Polyhedron, 2011, 30: 1857

[28] Kresge C T, Leonowicz M E, Roth W J, Vartuli J C, Beck J S. Nature, 1992, 359: 710

[29] Singh U G, Williams R T, Hallam K R, Alen G C. J Solid State Chem, 2005, 178: 3405

[30] Yang H Q, Zhang G Y, Hong X L, Zhu Y Y.J Mol Catal A, 2004, 210: 143

[31] Bai Sh Y, Yang H Q, Wang P, Gao J S, Li B, Yang Q H, Li C. Chem Commun, 2010, 46: 8145

[32] Mubofu E B, Clark J H, Macquarrie D J. Green Chem, 2001, 3: 23 


\title{
Graphical Abstract
}

Chin. J. Catal., 2013, 34: 1326-1332 doi: 10.1016/S1872-2067(12)60568-3

Nickel(II) complex anchored on MCM-41 for the epoxidation of styrene by oxygen

YANG Gang *, CHEN Xing, WANG Xiaoli, XING Weihong, XU Nanping Nanjing University of Technology

A nickel(II) Schiff base complex functionalized MCM-41 catalyst was used to catalyze epoxidation of styrene using green oxidant molecular oxygen as oxidant with styrene conversion of $95.2 \%$ and epoxide selectivity of $66.7 \%$

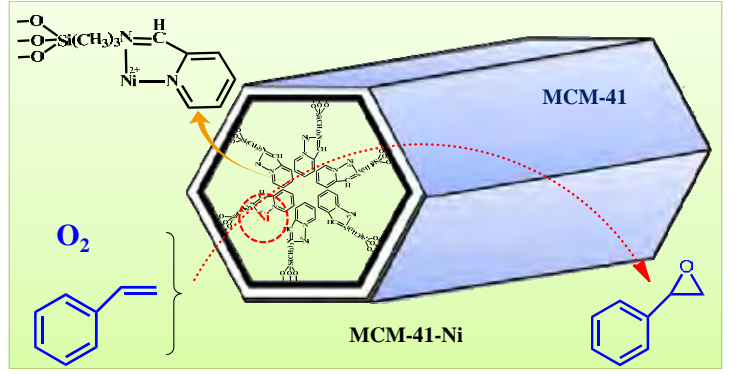

[33] Xu G, Xia Q H, Lu X H, Zhang Q Zhan H J. J Mol Catal A, 2007, 266 180

[34] Zhan H J, Xia Q H, Lu X H, Zhang Q, Yuan H X, Su K X, Ma X T. Catal Commun, 2007, 8: 1472
[35] Sebastian J, Jinka K M, Jasra R V.J Catal, 2006, 244: 208

[36] Shi X F, Shi B P, Fan B B, Li R F. Chin Chem Lett, 2012, 23: 53

[37] Cui H T, Zhang Y, Qiu Z G, Zhao L F, Zhu Y L. Appl Catal B, 2010, 101: 45

\section{镍(II)配合物官能化的MCM-41催化分子氧环氧化苯乙烯}

\author{
杨 刚, 陈 星, 王小丽, 邢卫红, 徐南平 \\ 南京工业大学材料化学工程国家重点实验室, 江苏南京210009
}

摘要: 制备了镍(II)席夫碱配合物官能化的MCM-41多相催化剂MCM-41-Ni. 利用X射线粉末衍射、氮气物理吸附脱附、红外光谱、 热重、电感耦合等离子体原子发射光谱、元素分析和透射电镜等方法对催化剂进行了表征. 以氧气为氧化剂, MCM-41-Ni在催化 环氧化苯乙烯的反应中表现出较高的催化活性; 苯乙烯的转化率为 $95.2 \%$, 环氧苯乙烷的选择性为 $66.7 \%$. 系统地研究了反应温度、 催化剂用量、溶剂以及反应时间对反应性能的影响. 催化剂经过4次循环仍然表现出较好的稳定性和催化活性.

关键词：镍席夫碱配合物; MCM-41分子篮; 苯乙烯环氧化; 分子氧

收稿日期: 2013-01-23. 接受日期: 2013-03-12. 出版日期: 2013-07-20.

*通讯联系人. 电话: (025)83172291; 传真: (025)83172292; 电子信箱: yanggang@njut.edu.cn

基金来源：国家自然科学基金(20576052).

本文的英文电子版由Elsevier出版社在ScienceDirect上出版(http://www.sciencedirect.com/science/journal/18722067). 